\title{
Predicting Satisfaction in Physical Education Classes: A Study Based on Self-Determination Theory
}

\author{
Roberto Ferriz, Álvaro Sicilia* and Piedad Sáenz-Álvarez \\ Universidad de Almería, Facultad de Educación, Enfermería y Fisioterapia, Departamento de Educación, Carretera de \\ Sacramento s/n, 04120 La Cañada de San Urbano, Almería, Spain
}

\begin{abstract}
This study aimed to analyse the relationships between the satisfaction of basic psychological needs, motivation and satisfaction in physical education classes, as well as to examine these relationships by gender. Eight hundred and fifty-four secondary school students (405 boys and 453 girls, aged 15 to 21 years) participated in this study by responding to questionnaires designed to measure the aforementioned variables. Two linear regression analyses were carried out alongside independent samples $t$-tests. Linear regression analyses showed that the satisfaction of autonomy, competition and relatedness needs, self-determined forms of motivation (i.e., intrinsic motivation, integrated regulation and identified regulation) and one of the non-self-determined motivations (i.e., introjected regulation) positively predicted satisfaction in physical education, whereas amotivation negatively predicted satisfaction. Independent samples $t$-tests revealed that the girls scored lower than the boys on all variables except for external regulation, for which they showed a higher average score than the boys. Furthermore, the differential analysis between genders showed that satisfaction of the need for competition did not predict satisfaction in physical education in the case of the girls. Differences were also found in the prediction weights of motivational regulation for the group of boys. The results of this study allow a better understanding about the motivational process that explains students' satisfaction within their physical education classes. They also emphasise the significant roles that satisfaction of the need for relatedness and intrinsic motivation play in increasing students' satisfaction in physical education.
\end{abstract}

Keywords: Adolescence, physical education, basic psychological needs, motivation, self-determination theory.

\section{INTRODUCTION}

Physical education (PE) classes can be an ideal environment for the promotion of physical activity and a healthy lifestyle among adolescents [1, 2]. Specifically, students' motivation and satisfaction with PE classes can influence their habits and behaviours over the long term and even throughout their adult lives [3, 4]. Therefore, it seems important to identify the motivational processes that precede satisfaction within PE classes in the interests of facilitating long-term commitments to healthy lifestyles. Currently, selfdetermination theory [SDT; 5, 6] seems to be a useful theoretical framework for understanding the psychological processes that likely underlie participation in and evaluation of PE experiences.

SDT helps to explain the process by which certain environments may facilitate or frustrate the satisfaction of an individual's basic psychological needs, which are considered foundational elements in the development of well-being [7]. The need for autonomy refers to those experiences in which individuals feel they are the sources of their actions and can determine their own behaviours. The need for competence refers to the sense of having executed a task efficiently and thereby of having developing individual skills. The need for relatedness refers to the way interactions with others take

*Address correspondence to this author at the Departamento de Educación, Universidad de Almería. Carretera de Sacramento s/n, 04120 La Cañada de San Urbano, Almería, Spain; Tel: +34 950015 394; E-mail: asicilia@ual.es place under the sense of belonging to a group. As it is shown in Fig. (1), within the motivational sequence established by SDT $[6,8]$, these three basic needs would mediate the impact of social factors on motivation and they would play a critical role in fostering self-determined motivation.

SDT conceptualises motivation as existing in various forms located across a continuum. The least self-determined extreme of the motivational continuum is described as lack of motivation or amotivation, reflecting a lack of interest in the behaviour at hand; conversely, intrinsic motivation, reflecting a person's internal interest in the activity itself, lies at the most self-determined extreme. Extrinsic motivation lies on the continuum between amotivation and intrinsic motivation and describes behaviour carried out for reasons external to the activity itself. Depending on the degree to which this external factor is integrated into personality, four types of extrinsic motivational regulations can be differentiated. First, external regulation, in which there is no internalisation of the behaviour, is the least self-determined form of extrinsic motivation. Externally regulated behaviour is executed to receive a reward or avoid a punishment. Second, introjected regulation presupposes a minimal process of internalisation of the behaviour-in other words; the individual participates in the activity in order to avoid feelings of guilt. Third, identified regulation implies one more step toward internalisation of the behaviour, as the individual begins to appreciate the importance and the potential benefits of the activity. Last, integrated regulation involves the maximum process of internalisation: the 


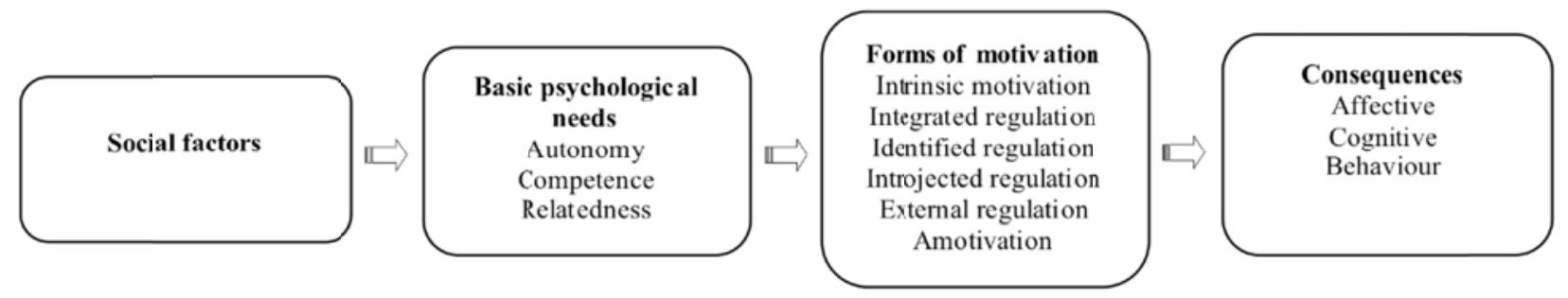

Fig. (1). Sequence of motivational processes established by SDT [6, 8].

individual incorporates the activity into his or her lifestyle and places it in consonance with the rest of his or her personal values. Research has shown that the forms of motivation on the self-determined end of the continuum (i.e., intrinsic motivation, integrated regulation and identified regulation) are related to more adaptive behaviours, such as an active lifestyle, increased self-esteem and satisfaction with or adherence to exercise, while non-self-determined forms of motivation (i.e., introjected regulation, extrinsic regulation and amotivation) are associated with non-adaptive consequences, such as giving up physical exercise [4, 9].

As of today, there are few studies associating the motivational variables of SDT with how satisfied students are with their PE classes. In a study of $428 \mathrm{PE}$ students aged 14 to 16 , Ntoumanis [10] showed that satisfaction within PE classes correlated positively with intrinsic motivation and identified, introjected and external forms of regulation but correlated negatively with amotivation. Ntoumanis also revealed through cluster analysis that high PE satisfaction scores corresponded to high scores in intrinsic motivation and identified regulation, average scores in introjected regulation, and low scores in external regulation and amotivation. In Spain, Gómez et al. [11], using a sampling of 684 PE students aged 11to 18, showed that satisfaction in PE was related negatively to amotivation, whereas GraneroGallegos et al. [12], upon sampling 2002 secondary school students aged 12 to 19 , showed that PE satisfaction was positively related to intrinsic motivation and to extrinsic motivation (measured with respect to identified, introjected and external regulation).

Although the aforementioned studies have provided evidence for the relationship between satisfaction in PE and several SDT-related variables, they do suffer from some limitations. First, the paper by Gómez et al. [11] only analysed the relationship between satisfaction and amotivation; additionally, it did not account for the remaining forms of motivation defined in SDT. Second, although the Granero-Gallegos et al. [12] research analysed intrinsic motivation, extrinsic motivation and amotivation, the study used a global measurement of the different types of extrinsic motivation (i.e., identified, introjected and external regulation), thereby failing to differentiate between selfdetermined and non-self-determined forms of regulation. Finally, although Ntoumanis's study [10] separately analysed the distinct forms of extrinsic motivation (i.e., selfdetermined and non-self-determined motivation), it did not consider one other form: integrated regulation. Analysing integrated regulation can be of great interest to researchers because satisfaction has been identified as a predictive variable for future participation in extracurricular activities and in post-compulsory education [13]; moreover, persistence in these activities appears to be associated, to a large degree, with integrated regulation [14]. Furthermore, none of the previously described studies incorporated satisfaction of the three basic psychological needs along with the various forms of motivation. This omission could be significant because SDT [6] conceptualises the different forms of motivation as being affected by the degree to which basic psychological needs are satisfied or frustrated by the social environment [15].

In light of the foregoing considerations, the goal of the present study was to analyse the degree to which satisfaction of basic psychological needs and the various forms of motivation (including integrated regulation) predict satisfaction in PE. Following the postulates of SDT and the studies reviewed above, it was hypothesised that the three basic psychological needs would positively predict satisfaction in PE. Furthermore, it was hypothesised that both the self-determined and the non-self-determined forms of motivation would positively predict satisfaction, whereas amotivation would be shown to be a negative predictor of satisfaction in PE.

A secondary goal of this study was to analyse gender differences in the variables under scrutiny and their influence in predicting PE satisfaction. As has been indicated in previous studies [11, 12], boys tend to report higher satisfaction scores for PE classes than girls. On the other hand, the research literature also has revealed differences between boys and girls with respect to their motives for and interest in participating in PE classes [16, 17]. For example, the Granero-Gallegos et al. study [12] showed that girls were mostly grouped in a low motivational profile characterised by high scores in amotivation and low scores in intrinsic motivation, extrinsic motivation and satisfaction in $\mathrm{PE}$ classes; in contrast, the high motivational profile was more represented by boys. In light of these previous data, the present study adopted the hypothesis that girls would show lower satisfaction scores toward PE classes compared with boys. Moreover, it was hypothesised that the non-selfdetermined forms of motivation would predict satisfaction in PE for both groups and that, for girls, the non-selfdetermined forms of motivation would also predict satisfaction in PE.

\section{METHOD}

\section{Participants}

Eight hundred and fifty-eight students ( 405 boys and 453 girls), between 15 and 21 years of age $(M=16.72 ; S D=$ $.84)$, were recruited from eleven high schools in Spain. The students received two weekly sessions of compulsory PE 
with duration of 55 minutes per session. The classes were co-educational and the majority of the students were of Caucasian race and of middle socioeconomic class. The majority of students reported doing physical activity in their free time $(88.8 \%$ of boys and $81.4 \%$ of girls). However, among those students who reported doing any physical activity, only $47.1 \%$ of boys and $23.9 \%$ of girls had begun six months earlier.

\section{Measures}

Satisfaction in PE classes. The Spanish version of PE classes [18] of the Physical Activity Class Satisfaction Questionnaire [19] was used. Participants were instructed to indicate their level of satisfaction in PE classes. The instrument is composed of a total of 33 items grouped under nine factors. The items are scored on a Likert scale of 1 (strongly disagree) to 8 (strongly agree). In this study, a Cronbach's alpha value of .92 was obtained for the factor of improvement of health, .91 for cognitive development, .90 for relaxation, .89 for normative success, .89 for diversionary experiences, .89 for teaching, .88 for fun, .86 for mastery experiences, and .80 for interaction with others. The psychometric properties of both a nine-factor model and a higher-order model measuring the global construct of satisfaction have been previously tested in the Spanish context [see; 18].

Basic psychological needs in PE. The Spanish version for PE [20] of the Basic Psychological Needs in Exercise Scale [21] was used. The scale is introduced by the sentence "In my PE classes" and is composed of a total of 12 items (four per each factor) that measure the need for autonomy (e.g., "I feel very strongly that the way I exercise fits perfectly the way I prefer to exercise"), the need for competence (e.g., "I feel I have been making a huge progress with respect to the end result I pursue") and the need for relatedness (e.g., "I feel that I associate with the other exercise participants in a very friendly way"). The answers are scored on a Likert scale of 1 (strongly disagree) to 5 (strongly agree). In this study, a Cronbach's alpha value of .82 was obtained for the need for autonomy, .78 for the need for competence and .83 for the need for relatedness.

Motivation in PE classes. The Spanish version of the Perceived Locus of Causality (PLOC) scale [22] was used. This instrument integrated the PLOC scale of five items adapted to Spanish context by Moreno, González-Cutre, y Chillón [23] and the four items established by Wilson, Rodgers, Loitz, y Scime [24] to measure the integrated regulation. The scale is introduced by the sentence "I take part in physical education class..." and is composed of a total of 24 items that measure intrinsic motivation (e.g., "because I enjoy learning new skills"), integrated regulation (e.g., "because participation in physical education is consistent with my deepest principles") identified regulation (e.g., "because it is important for me to do well in physical education"), introjected regulation (e.g., "because I would feel bad about myself if I didn't"), external regulation (e.g., "so that the teacher won't yell at me") and amotivation (e.g., "but I really feel I'm wasting my time in physical education"). Answers are scored on a Likert scale of 1 (strongly disagree) to 7 (strongly agree). A Cronbach's alpha value of .84 was obtained for intrinsic motivation, .93 for integrated regulation, .84 for identified regulation, .69 for introjected regulation, .69 for external regulation and .82 for amotivation.

\section{Procedure}

Authorisation to conduct the study was requested from school administrators and from the PE teachers who were asked to give over part of the time of one of their classes to administer the questionnaires. Students of legal age were requested to give their own signed authorisations to participate, whereas underage students were asked to have their parents provide signed authorisation. The anonymous questionnaires were filled out in class in the presence of the principal investigator, who explained the relevance of the study and its procedures. Instruments were collected on an individual basis to assure that no item went unanswered. The students took approximately 25 minutes to answer the questionnaire.

\section{Data Analysis}

To analyse the effects of satisfaction of the basic psychological needs and the different types of motivation on PE satisfaction, a linear regression analysis was performed. Following the postulates of SDT, an initial step introduced the basic psychological needs into the model; the forms of motivation were incorporated in a second step. Next, independent samples $t$-tests were conducted in order to compare the averages of the target variables by gender. Then, a new linear regression analysis was performed to observe if the relationships between the variables were equivalent between boys and girls.

\section{RESULTS}

Effects of the Basic Psychological Needs and Types of Motivation on Satisfaction in PE

As shown in Table 1, the needs for autonomy, competence and relatedness positively predicted satisfaction within PE classes. Furthermore, intrinsic motivation as well as the various forms of extrinsic motivation (excepting external regulation) positively predicted satisfaction in PE, whereas amotivation negatively predicted satisfaction. The total variance explained was $81 \%$. However, the predictive value of the basic psychological needs was shown to be greater than that of the forms of motivation: the former explained $71 \%$ of PE satisfaction's variance, while the latter increased the variance explained by only $10 \%$.

\section{Mean Differences Between Boys and Girls}

The results of the independent samples $t$-tests (Table 2) revealed that the averages of the boys' scores were higher than those of the girls for all variables except external regulation, for which the girls reported an average score. According to the criterion established by Cohen [25], all variables showed a large effect size $(d>|0.8|)$, with the exception of amotivation which showed a medium effect size.

\section{Differences in Prediction Effects by Gender}

As shown in Table $\mathbf{3}$, the needs for autonomy, competence and relatedness positively predicted satisfaction in PE for the group of boys, whereas only two of the needsautonomy and relatedness-did so for the girls. With regard to the effects of motivation, two forms of self-determined motivation-intrinsic and identified motivation-positively 
Table 1. Regression Analysis Predicting Satisfaction (Dependent Variable) from Basic Psychological Needs and Motivational Regulations (Independent Variables)

\begin{tabular}{|c|c|c|c|c|}
\hline & $\boldsymbol{F}$ & $R^{2}$ & $\beta$ & $t$ \\
\hline Step 1 & 692.69 & $.71 * * *$ & & \\
\hline Autonomy & & & .28 & $11.47 * * *$ \\
\hline Competence & & & .25 & $10.62 * * *$ \\
\hline Relatedness & & & .51 & $24.51 * * *$ \\
\hline Step 2 & 401.47 & $.81 * * *$ & & \\
\hline Autonomy & & & .20 & $9.78 * * *$ \\
\hline Competence & & & .07 & $3.10 * *$ \\
\hline Relatedness & & & .41 & $22.81 * * *$ \\
\hline Intrinsic motivation & & & .21 & $7.06 * * *$ \\
\hline Integrated regulation & & & .09 & $3.05 * *$ \\
\hline Identified regulation & & & .09 & $2.98 * *$ \\
\hline Introjected regulation & & & .07 & $3.16^{* *}$ \\
\hline External regulation & & & .00 & .14 \\
\hline Amotivation & & & -.07 & $-3.78 * * *$ \\
\hline
\end{tabular}

predicted satisfaction in PE for the boys, whereas satisfaction in PE was positively predicted by two forms of self-determined motivation (intrinsic motivation and integrated regulation) and one form of non-self-determined motivation (introjected regulation) for the girls. Additionally, amotivation was shown to be a negative predictor of satisfaction in PE for the girls. The explained variance of satisfaction in PE was somewhat higher in the case of the boys than in that of the girls.

\section{DISCUSSION}

This study aimed to analyse the predictive effects that the basic psychological needs and types of motivation have on individuals' satisfaction within PE class. A secondary objective was to identify any gender differences that might exist amongst these relationships. The results of this research represent a step forward in the field because, up until now, the basic psychological needs and types of motivation (including integrated regulation) had not been studied together with respect to satisfaction in PE. The hypotheses established for the study were partially confirmed, although some observed relationships were not initially expected.

First, the results of the present study emphasise the predominant role that satisfaction of the need for relatedness appears to play in predicting students' satisfaction in PE. These results are in line with the postulates of SDT [6] and previous related research [15], which suggest that satisfaction of the basic psychological needs will have greater influence on the development of adaptive behaviours for an individual than will his or her own reasons for participating in the activity. The results of this study also corroborate other investigations' $[10,12]$ findings that both self-determined and non-self-determined motivation can be used to predict the satisfaction of students with their PE classes, with amotivation showing a negative relation with PE satisfaction. These detailed findings notwithstanding, intrinsic motivation appear to be the form of motivation most strongly predictive of satisfaction in PE. This finding coheres with the definition established by SDT [5] because the essence of intrinsic motivation is rooted in the enjoyment of the activity itself. Studies have indicated that enjoyment is a basic component of satisfaction with physical practise [26]; along these lines, Cunningham's study [19] found that $75 \%$ of the students consulted reported that fun and enjoyment were the main sources of satisfaction in classes with physical activity. Thus, it seems highly unlikely that a student will judge a PE class to be satisfactory if he or she finds it boring and unpleasant.

Although one non-self-determined form of motivation (i.e., introjected regulation) positively predicted satisfaction, its relationship with satisfaction was weaker than those with self-determined forms of motivation. Furthermore, this association does not seem out of place within the academic context, insofar as a student can feel satisfied simply by being responsible and fulfilling the academic obligation component of PE. On the other hand, one should not forget

Table 2. Mean Differences Between Boys and Girls in Basic Psychological Needs, Motivational Regulations and Satisfaction

\begin{tabular}{|c|c|c|c|c|c|c|c|}
\hline & & \multicolumn{2}{|c|}{ Boys } & \multicolumn{2}{|c|}{ Girls } & \multirow[b]{2}{*}{$t$ (388) } & \multirow[b]{2}{*}{ Cohen's $d$} \\
\hline & Range & $M$ & $S D$ & $M$ & $S D$ & & \\
\hline Autonomy & $1-5$ & 3.23 & .92 & 3.05 & .82 & $2.98 * *$ & .21 \\
\hline Competence & $1-5$ & 3.79 & .77 & 3.40 & .84 & $7.07 * * *$ & .48 \\
\hline Relatedness & $1-5$ & 4.02 & 1.43 & 3.81 & 1.58 & $2.12 *$ & .14 \\
\hline Intrinsic motivation & $1-7$ & 4.98 & 1.25 & 4.63 & 1.31 & $4.01 * * *$ & .27 \\
\hline Integrated regulation & $1-7$ & 5.03 & 1.49 & 4.21 & 1.56 & $7.80 * * *$ & .54 \\
\hline Identified regulation & $1-7$ & 5.00 & 1.37 & 4.71 & 1.32 & $3.17 * *$ & .08 \\
\hline Introjected regulation & $1-7$ & 4.05 & 1.42 & 3.81 & 1.28 & $2.29 *$ & .18 \\
\hline External regulation & $1-7$ & 3.41 & 1.40 & 3.73 & 1.30 & $-3.45 * *$ & -.24 \\
\hline Amotivation & $1-7$ & 2.50 & 1.46 & 2.41 & 1.37 & .88 & .06 \\
\hline Satisfaction & $1-8$ & 5.30 & 1.36 & 4.97 & 1.29 & $3.69 * * *$ & .25 \\
\hline
\end{tabular}


Table 3. Regression Analysis Predicting Satisfaction (Dependent Variable) from Basic Psychological Needs and Motivational Regulations for Boys and Girls (Independent Variables)

\begin{tabular}{|c|c|c|c|c|}
\hline & $\boldsymbol{F}$ & $R^{2}$ & $\beta$ & $t$ \\
\hline \multicolumn{5}{|l|}{ Boys } \\
\hline Step 1 & 428.00 & $.76 * * *$ & & \\
\hline Autonomy & & & .28 & $9.16^{* * *}$ \\
\hline Competence & & & .23 & $7.50 * * *$ \\
\hline Relatedness & & & .54 & $19.08 * * *$ \\
\hline Step 2 & 214.66 & $.83 * * *$ & & \\
\hline Autonomy & & & .19 & $6.93 * * *$ \\
\hline Competence & & & .06 & $3.29 * *$ \\
\hline Relatedness & & & .43 & $16.11^{* * *}$ \\
\hline Intrinsic motivation & & & .21 & $4.96^{* * *}$ \\
\hline Integrated regulation & & & .06 & 1.73 \\
\hline Identified regulation & & & .09 & $2.16^{*}$ \\
\hline Introjected regulation & & & .05 & 1.55 \\
\hline External regulation & & & -.02 & -.73 \\
\hline Amotivation & & & -.03 & -1.10 \\
\hline \multicolumn{5}{|l|}{ Girls } \\
\hline Step 1 & 285.09 & $.65 * * *$ & & \\
\hline Autonomy & & & .27 & $6.97 * * *$ \\
\hline Competence & & & .25 & $6.62 * * *$ \\
\hline Relatedness & & & .49 & $16.22 * * *$ \\
\hline Step 2 & 184.20 & $.79 * * *$ & & \\
\hline Autonomy & & & .21 & $6.76^{* * *}$ \\
\hline Competence & & & .04 & 1.32 \\
\hline Relatedness & & & .41 & $16.16^{* * *}$ \\
\hline Intrinsic motivation & & & .21 & $4.92 * * *$ \\
\hline Integrated regulation & & & .11 & $2.75 * *$ \\
\hline Identified regulation & & & .08 & 1.74 \\
\hline Introjected regulation & & & .08 & $2.63 * *$ \\
\hline External regulation & & & .02 & .86 \\
\hline Amotivation & & & -.10 & $-3.68 * * *$ \\
\hline
\end{tabular}

${ }^{*} p<.05 ; * * p<.01 ; * * * p<.001$.

the efforts being made by public institutions [27, 28] to promote physical activity (PA) among young people through PE classes, which could encourage feelings of guilt for not actively participating in these classes.

Second, these results reveal that boys report higher scores than girls in satisfaction in $\mathrm{PE}$ in the three basic psychological needs and in the various forms of motivation, with external regulation being the sole exception. These results conform to those of previous, related research [16, 29]. For instance, some studies have indicated that boys tend to assign greater value to PE classes than do girls [16, 29]. Moreover, boys tend to perceive greater satisfaction of their basic psychological needs in PE [30] and show higher scores in the intrinsic and extrinsic types of motivation [12]. As suggested by some investigators, these results may suggest that PE classes are better adapted to the interests of boys than to the interests of girls $[11,31]$. Future research and PE teachers should pay particular attention to the way in which $\mathrm{PE}$ classes can create social environments that improve satisfaction for girls.

The gender-differentiated regression analysis revealed that the need for competence did not predict satisfaction in PE for the girls but was a predictor for the boys. These results may reflect the fact that, for girls, demonstrating competence during PE classes is not as relevant to achieving satisfaction as it is for boys. These results make sense if one 
considers the studies [32, 33] that have suggested that, during physical activity and, particularly, competitive activities such as sports, boys feel a greater need to demonstrate their abilities to others than do girls. On the other hand, motivation appears to take on a more prominent role for girls than for boys. In fact, the percentage of variance in the model explained by the various forms of motivation was double for the girls what is was for the boys.

With respect to motivational forms, the results of the study partially support the hypotheses. The self-determined forms of motivation (i.e., integrated or identified regulation) predicted satisfaction for both groups, whereas one non-selfdetermined form of motivation-introjected regulationshowed a positive effect on satisfaction for the girls. One possible explanation for this finding on girls' introjected regulation can be derived from the information reported by the girls related to physical activity (PA). A high percentage of the girls (81.4\%) reported engaging in PA; this number contrasts with the low percentage (23.9\%) of the girls who reported doing so over the last six months. It is possible that the limited time dedicated to physical activity reported by the girls compared to the boys reflects a lesser degree of internalisation of exercise behaviour. On the other hand, introjected regulation reflects a type of pressure that has been internalised to some degree, insofar as the reason for doing the activity is to avoid feeling guilty for failing to complete an obligatory activity. Thus, fulfilling the obligation of participating in PE could, in itself, provide satisfaction for girls. This hypothesis is supported by the fact that girls may be particularly sensitive to social pressure in the context of behaviours related to physical activity [34]. Future research would do well to address these possible hypotheses.

Finally, in keeping with previous research [10, 12], this study had hypothesised that amotivation would negatively predict satisfaction in PE for both genders. Although this prediction was confirmed for the entire sample, the genderdifferentiated analysis demonstrated that this effect disappears for the exclusively male sample. One possible explanation lies in the fact that the effect of the types of motivation on satisfaction in PE was smaller for boys than for girls; this may have diminished the negative predicting effect of amotivation in the case of the boys.

In spite of its contributions, one needs to keep in mind some of the study's limitations. First, although this is the first time that psychological needs and integrated regulation have been related to satisfaction, this study has not considered the social factors of SDT that could also help explain satisfaction within PE classes. For example, it would be interesting to investigate the extent to which student satisfaction in PE is be influenced by the instructor's facilitation or frustration of the development of psychological needs. Second, although the directionalities of the relationships articulated in the study design are plausible, other interpretations are possible. For example, in this study, satisfaction is considered a consequence within the hypothesised SDT model. However, future studies might also consider the role this variable plays as a social factor. Finally, given the cross-sectional design of the study, relations cannot be considered causal. Longitudinal and experimental studies would be required to verify the causality of the observed relationships.
In sum, the results of this research suggest that satisfaction of the basic psychological needs, particularly the need for relatedness, better predicts satisfaction in PE than do the various forms of motivation. The results also indicate that intrinsic motivation is the motivational variable showing the most association with satisfaction in PE. Thus, the results suggest that, in order to promote student satisfaction in PE, schools and PE faculty should promote educational environments that satisfy their students' needs for relatedness, competence and autonomy by generating experiences in which students have fun and enjoy themselves.

\section{CONFLICT OF INTEREST}

The authors confirm that this article content has no conflict of interest.

\section{ACKNOWLEDGEMENTS}

This work was carried out with the aid of the research project entitled "Analysis of the influence of physical education classes in physical activity adherence and adoption of healthy lifestyle habits after concluding compulsory education" (Ref. DEP2010-17063), funded by the Ministerio de Ciencia e Innovación, Spain.

\section{REFERENCES}

[1] Cale L. Physical activity promotion in secondary schools. Eur Phys Educ Rev 2000; 6: 71-90.

[2] McKenzie TL. Promoting physical activity in youth: focus on middle school environments. Quest 2001; 53(3): 326-34.

[3] Beggs BA, Elkins DJ. The influence of leisure motivation on leisure satisfaction. Journal [serial on the Internet]. 2010. Available from: http://larnet.org/2010-02.html

[4] Hagger MS, Chatzisarantis NLD. The trans-contextual model of motivation. In: Hagger MS, Chatzisarantis NLD, editors. Intrinsic motivation and self-determination in exercise and sport. Champaign, IL: Human Kinetics 2007; pp. 53-70.

[5] Deci EL, Ryan RM. Intrinsic motivation and self-determination in human behavior. New York: Plenum 1985.

[6] Deci EL, Ryan RM. The "what" and "why" of goal pursuits: Human needs and the self-determination of behavior. Psychol Inq 2000; 11: 227-68.

[7] Deci EL, Ryan RM. Handbook of self-determination research. Rochester NY: University of Rochester Press 2002.

[8] Vallerand RJ. A hierarchical model of intrinsic and extrinsic motivation for sport and physical activity. In: Hagger MS, Chatzisarantis NLD, Eds. Intrinsic motivation and selfdetermination in exercise and sport. Champaign, IL: Human Kinetics 2007; pp. 255-79.

[9] Moreno JA, Cervelló E. Motivación en la actividad física y el deporte. Sevilla: Wanceulen 2010.

[10] Ntoumanis N. Motivational clusters in a sample of British physical education classes. Psychol Sport Exerc 2002; 3: 177-94.

[11] Gómez A, Gámez S, Martínez I. Efectos del género y la etapa educativa del estudiante sobre la satisfacción y la desmotivación en Educación Física durante la educación obligatoria. Ágora 2011; 13(2): 183-95.

[12] Granero-Gallegos A, Baena-Extremera A, Pérez-Quero FJ, OrtizCamacho MM, Bracho-Amador C. Analysis of motivational profiles of satisfaction and importance of physical education in high school adolescents. J Sport Sci Med 2012; 11: 614-23.

[13] Carlon TB. We hate gym: student alienation from physical education. J Teach Phys Educ 1995; 4: 467-77.

[14] Duncan LR, Hall CR, Wilson PM, Jenny O. Exercise motivation: a cross-sectional analysis examining its relationships with frequency, intensity, and duration of exercise. Int J Behav Nutr Phys Act 2010; 7: 7 .

[15] Hagger MS, Chatzisarantis NLD, Barkoukis V, Wang CKJ, Baranowski J. Perceived autonomy support in physical education 
and leisure-time physical activity: A cross-cultural evaluation of the trans-contextual model. J Educ Psychol 2005; 97: 376-90.

[16] Moreno JA, Hellín MG. El interés del alumnado de educación secundaria obligatoria hacia la educación física. [serial on the Internet]. 2007; 9(2): Available from: http://redie.uabc.mx/vol9no 2/contenido-moreno.html

[17] Moreno JA, Martínez C, Alonso N. Actitudes hacia la práctica físico-deportiva según el sexo del practicante. Int J Sport Sci 2006; 2(3): 20-43.

[18] Sicilia A, Ferriz R, Trigueros R, González-Cutre D. Adaptación y validación española del physical activity class satisfaction questionnaire (PACSQ). [En revisión].

[19] Cunningham GB. Development of the physical activity class satisfaction questionnaire (PACSQ). Meas Phys Educ Exerc Sci 2007; 11: 161-76.

[20] Moreno JA, González-Cutre D, Chillón M, Parra N. Adaptación a la educación física de la escala de las necesidades psicológicas básicas en el ejercicio. Rev Mex Psicol 2008; 25: 295-303.

[21] Vlachopoulos SP, Michailidou S. Development and initial validation of a measure of autonomy, competence, and relatedness in exercise: the basic psychological needs in exercise scale. Meas Phys Educ Exerc Sci 2006; 10: 179-201.

[22] Sicilia A, Ferriz R, González-Cutre D. Revisión de la Escala del Locus Percibido de Causalidad (PLOC) para la inclusión de la medida de la regulación integrada en educación física. [En revisión].

[23] Moreno JA, González-Cutre D, Chillón M. Preliminary validation in Spanish of a scale designed to measure motivation in physical education classes: the Perceived Locus of Causality (PLOC) Scale. Span J Psychol 2009; 12: 327-37.

[24] Wilson PM, Rodgers WM, Loitz CC, Scime G. It's who I am ... really! The importance of integrated regulation in exercise contexts. J Appl Biobehav Res 2006; 11: 79-104.
[25] Cohen J. Statistical power analysis for the behavioral sciences. $2^{\text {nd }}$ ed. Hillsdale, NJ: Lawrence Earlbaum Associates 1988.

[26] Rossman JR. Recreation programming: Designing leisure experiences. $2^{\text {nd }}$ ed. Champaign, IL: Sagamore Publishing 1995.

[27] ConsejoSuperiordeDeportes. Plan integral para la actividad física y el deporte. Consejo Superior de Deportes ed. Madrid: Consejo Superior de Deportes 2010.

[28] ConsejoSuperiordeDeportes. Directrices de actividad física de la UE. Actuaciones recomendadas para apoyar la actividad física que promueve la salud. Madrid: Consejo Superior de Deportes; 2010 [cited. Available from: https://sede.educacion.gob.es/publiventa/de talle. action? $\operatorname{cod}=13546$.

[29] Cervelló E, Santos-Rosa FJ. Motivación en las clases de educación física: un estudio de la perspectiva de las metas de logro en el contexto educativo. Rev Psicol Deporte. 2000; 9: 51-70.

[30] Bagøien T, Halvari H, Nesheim H. Self-determined motivation in physical education and its links to motivation for leisure-time physical activity, physical activity, and well-being in general Percept Mot Skills 2010; 111(2): 407-32.

[31] Baena-Extremera A, Granero-Gallegos A, Bracho-Amador C, Pérez-Quero FJ. Spanish version of the sport satisfaction instrument (SSI) adapted to physical education. Rev Psicodidáctica. 2012; 17(2): 377-95.

[32] Moreno JA, González-Cutre D. Predicción del disfrute en el ejercicio físico según la orientación disposicional y la motivación autodeterminada. Anál Modif Conducta. 2006; 32: 767-80.

[33] Sicilia A. La investigación sobre el pensamiento del alumnado. Una revisión desde la educación física. Rev Educ 2002; 331: 577613.

[34] Hagger MS, Stevenson A, Chatzisarantis NLD, Pereira Gaspar PM, Leitão Ferreira JP, González Ravé JM. Physical self-concept and social physique anxiety: Invariance across culture, gender and age. Stress Health 2010; 26: 304-29. 